\title{
Homenaje a Michel Foucault: Treinta años después
}

\section{Harold Viafara Sandoval'}

Referencia formato APA: Viafara, H. (2015). Homenaje a Michel Foucault: Treinta años después. Revista Científica Guillermo de Ockham, 13(1), 137-140.

Los desarrollos teóricos propuestos por Michel Foucault dejan instaladas las bases de un pensamiento comprensivo. Foucault aportó una especie de caja de herramientas para abordar diversos tópicos teóricos que han preocupado de manera reiterada a las ciencias sociales.

\section{Foucault infante, estudiante, practicante y profesor}

Del matrimonio del médico y destacado anatomista Paul-Andre Foucault y de Anne-Marie Malapert, nace en Poitiers el 15 de octubre de 1926, Michel Foucault. Su hermana mayor, Francine, había nacido un año antes y en 1933 nace su hermano menor Denys (Castro, 2014). A los cuatro años ingresa a la clase de jardín de infantes en el Lycée Henri-IV, en Poitiers, con un permiso especial debido a su edad, a fin de no ser separado de su hermana mayor. En mayo de 1940, los hermanos Foucault son enviados a la propiedad de la familia en Vendeuvre-duPoitou, hogar de su abuela Raynaud-Malapert, mientras que el ejército alemán invade Francia (Defert, 2013).

En el liceo, Foucault tendrá su primer encuentro con niños españoles refugiados (1936). Pese a su corta edad, en 1937 sorprende a su padre -quien le había pronosticado una carrera como cirujano- con el anuncio de que va a convertirse en profesor de historia, algo inaceptable para la familia a menos que dicho "desacato" se cumpliese en la prestigiosa Sorbona.

El conflicto europeo generaría un sinnúmero de situaciones, entre ellas la interrupción de la vida escolar, razón por la cual en el último trimestre de 1941 el pequeño Michel es matriculado en la escuela secundaria de Saint-Stanislas, cuya dirección se encontraba a cargo de los hermanos cristianos de La Salle. En junio de 1942 termina su bachillerato a una edad temprana, momento que coincide con el ingreso a la resistencia de su profesor de filosofía, situación que no pasará inadvertida para el joven Paul-Michel. Esta circunstancia obliga a su madre a organizarle clases privadas de filosofía con Louis Girard, un estudiante que se haría conocido años después en Poitiers por sus lecturas del Manifiesto comunista. Su madre mientras tanto, se encargaría de la escuela y contrata a un benedictino de la abadía de Ligugé, Dom Pierro, para las clases de filosofía (Defert, 2013). En 1943 aprueba el examen del bachillerato en el Lycée Henri-IV e inicia allí mismo su preparación para el ingreso a la École Normale Supérieure (Castro, 2014).

En 1945 solicita su admisión pero es rechazado, situación que lo obliga a ingresar a la Khâgne $e^{2}$ para completar su formación y será en Julio de 1946 cuando es finalmente admitido. Su paso por esa institución le granjeará amistad con Maurice Pinguet, Robert Mauzi, Pierre Bourdieu, Jean-Claude Passeron, Jean-Pierre Serre y Paul Veyne, entre otros. Su vida personal aquí tuvo momentos difíciles surgidos de la angustia por su homosexualidad.

En 1948 Foucault recibe el título de Licenciatura en Filosofía y en ese mismo año tiene un primer intento de suicidio producto de una crisis depresiva. Sus cuatro años de formación en la École estuvieron marcados por su interés en los cursos de Maurice Merleau-Ponty, quien una vez nombrado profesor de psicología infantil en la Sorbona da su famoso curso sobre las ciencias del hombre y la fenomenología e introduce a los estudiantes de la École Normale en el trabajo de Ferdinand de Saussure. Esto llamará poderosamente la atención de Foucault, quien calificaría su pensamiento como formal en oposición al estructuralismo (Defert, 2013). Su profesor de filosofía será Jean Hyppolitte (Castro, 2014).

En 1949 obtiene una licenciatura en psicología -disciplina que lo fascinó toda su vida-, año en el cual vuelve a ser víctima de un estado depresivo que lo sume en el alcohol y las drogas (Defert, 2013). Frente a ello se dirá que Foucault era un adicto, pero solamente recurría a ellas durante episodios controlados y separados por varios meses, pues el placer de escribir, trabajar y enseñar le bastaba para acotar toda clase de desbordamiento (Veyne, 2009).

1. Profesor asociado de la Facultad de Educación Universidad de San Buenaventura Cali. E-mail: hviafara@usbcali.edu.co, harvisa@hotmail.com

2. Khâgne es el segundo ańo de las clases preparatorias para ingresar a las grandes écoles y son muy selectivas. 
En 1950 fracasa en la obtención de su agrégation (examen de Estado para ser profesor), lo que lo conduce a un nuevo intento de suicidio. Posteriormente, inicia un tratamiento psicoterapéutico y otro contra el alcohol.

En octubre de 1951 aprueba el examen de la agrégation y se convierte en profesor asistente de psicología en la École Normale y trabaja como psicólogo en el laboratorio de electroencefalografía del doctor Verdeaux y su esposa Jacqueline, a quien había conocido en Poitiers durante la guerra. Como becario de la Fundación Thiers, comienza su tesis en el postcartesianismo y el nacimiento de la psicología. Cautivado por Malebranche y Maine de Biran, pasa un tiempo con Ignace Meyerson, director de la revista de Psychologie Normale et Pathologique (Defert, 2013).

En 1952 hace prácticas como psicólogo en la unidad del Profesor Delay's, donde Henri Laborit está probando la primera droga neuroléptica que marcaría el comienzo de una revolución psiquiátrica. En junio del mismo año obtiene su diploma de Especialización en Psicopatología en el Instituto de Psicología de París. Deja la Fundación Thiers y se convierte en investigador en psicología en la Facultad de Artes de Lille, donde, según Canguilhem (2005), Ombredane, el traductor de Rorschach, estaba buscando a alguien competente en psicología experimental. Posteriormente, en junio de 1953 recibe su diploma de Especialización en Psicología Experimental del Instituto de Psicología de París (Defert, 2013).

En 1953 asiste al seminario de Jacques Lacan y visita en Suiza a Ludwig Binswanger. Por esos tiempos inicia una relación amorosa con el músico Jean Barraqué (Castro, 2014) y en agosto de 1953 revelará que su llegada a Nietzsche la hizo a través de Bataille y a Bataille a través de Blanchot, del mismo modo que se acercó a Nietzsche por Heidegger.

Una serie de acontecimientos escriturales emergen con fuerza en septiembre del año 1953. Lacan da su famoso discurso de Roma Función y campo de la palabra y lenguaje en psicoanálisis; Gilles Deleuze publica Empirismo y subjetividad, su primer libro, dedicado a Jean Hyppolite y en octubre Foucault da un curso sobre El conocimiento del hombre y la reflexión trascendental y dicta algunas conferencias sobre Nietzsche, influenciado por sus escritos de 1880. En su seminario en la École Normale trabaja en Freud y Kant y la antropología y en 1954 publica Enfermedad mental y personalidad. Para 1958 se traslada a Varsovia y concluye la redacción de su tesis principal de doctorado Locura y sinrazón, bajo la dirección de Georges Canguilhem, quien tal vez fuera el que ejerció mayor influencia sobre él. A raíz de la muerte de su padre (1959), se traslada a Hamburgo y escribe su tesis secundaria de doctorado Gènese et structure de l'anthropologie de Kant (publicado en castellano como Una lectura de Kant), con la dirección de Jean Hyppolitte (Castro, 2014).

En 1960, de regreso a Francia es nombrado profesor de psicología en la Universidad de Clermont-Ferrand. Conoce a Daniel Defert, quien será su pareja durante casi veinticinco años. El 20 de mayo de 1961 somete a juicio sus dos tesis de doctorado en la Sorbona (Defert, 2013). Luego publica en el mismo año Locura y sinrazón e Historia de la locura en la época clásica. En 1962, publica Enfermedad mental y psicología y conoce a Gilles Deleuze, a quien le reconoce su perspectiva teórica.

\section{Foucault en "militancia"}

Hacia 1950 se une al Partido Comunista Francés por influencia de Louis Althusser. Para la época (1952-1955), emerge una situación que llama la atención en la École Normale, varios casos de intento de suicidio, entre ellos el de Foucault, quien pese a sus reservas respecto del psicoanálisis, acude al doctor Gallot (Defert, 2013). Tres años después (1953) abandona el PCF y en 1977 participa en una declaración contra las condenas a muerte del régimen de Franco. Será 1982 cuando viaja a Polonia y visita Auschwitz, pero no obtiene el permiso para encontrarse con Lech Walesa a pesar de que Foucault era el tesorero del Comité de Apoyo Internacional al movimiento polaco Solidaridad (Castro, 2014).

\section{Foucault en activismo}

En 1954, se crea en París la revista Arcadie, órgano de difusión de la primera asociación de hemofílicos. El 15 de octubre del mismo año, Georges Dumézil, filólogo e historiador francés, le informa por carta acerca de la vacante del cargo de traductor de francés, asistente y director de la Casa de Francia de Uppsala (Suecia), que él mismo había liderado veinte años atrás. En diciembre de 1955, Foucault acoge a Jean Hyppolite en Suecia y dicta sus conferencias Historia y existencia y Hegel y Kierkegaard en el pensamiento francés contemporáneo.

En 1965 emprende un viaje a a Sao Paulo donde dicta una serie de conferencias. Allí, Foucault dirá que solo en Brasil y en Túnez encontró estudiantes tan serios y apasionados por la avidez absoluta de saber. Volverá a Río de Janeiro en 1973 y 1974 a un ciclo de conferencias. En 1981 invita a Fernando Henrique Cardoso al Collège de France (Castro, 2014). 
En octubre de 1966 parte hacia Túnez donde se desempeña como profesor de filosofía. En 1968 regresa a Francia y dirige el Departamento de Filosofía de la recién creada universidad de Vincennes. Lee a Rosa Luxemburgo, al Che Guevara y se compromete con las filosofías políticas y las luchas de los Panteras Negras.

En 1970, cuando es nombrado en el Collège de France, viaja a la Universidad de Buffalo en EE. UU, Japón e Italia. En 1971 se anuncia la creación del Grupo de Información sobre las Prisiones (GIP) y llega a Canadá por invitación de la Universidad McGill. En 1975 visita la Universidad de Columbia e igualmente hace una estancia en Sao Paulo. En 1976, dicta una serie de conferencias en Montreal, Berkeley y Stanford. En 1978 hace un viaje a Japón donde da varias conferencias e igualmente se moviliza a Irán como periodista. Entre 1979 y 1980 realiza conferencias en Stanford, Berkeley, Nueva York y Dartmouth (Castro, 2014).

\section{Foucault en el del Collège de France}

Foucault es nombrado en el año de 1970 en el Collège de France para ocupar la cátedra Historia de los sistemas de pensamiento en remplazo de Jean Hyppolite. Allí presenta como lección inaugural $E l$ orden del discurso y se gesta gran parte de su concepción política al lado de pensadores como Raymond Aron, Roland Barthes, Henri Bergson, Pierre Bourdieu, Fernand Braudel, Lucien Febvre, Claude Lévi-Strauss, Maurice Merleau-Ponty, Paul Valéry y Paul Veyne (Defert, 2013). Su paso por este centro le brindó el ambiente propicio para estructurar su trabajo investigativo y académico. En los archivos del Collège la publicación de su lección inaugural se registra así: Michel Foucault, Histoire des systèmes de pensée, Collège de France (épuisé).

Las clases de Foucault en el Collège de France atraían a una verdadera muchedumbre, como en otros tiempos sucedía con Henri Bergson. A ellas acudían personalidades conocidas, gente del teatro y hasta un antiguo secretario de Stalin (Veyne, 2009, p. 156), lo que revela en Foucault un escritor, un pensador y el gestor de una propuesta analítica comprensiva.

En 2007 fue considerado por el The Times Higher Education Guide como el autor más citado del mundo en el ámbito de las humanidades, hecho que corresponde a la característica de un pensador cuya huella sentó un precedente en el pensamiento universal. Su trabajo incentivó en el ámbito académico la escritura de varios dossiers, como A companion to Foucault, puesto a consideración de los lectores por Blackwell Companions to Philosophy, editado por Christopher Falzon, Timothy O'Leary y Jana Sawicki (2013). La particularidad de esta publicación es la facultad que posee de reunir diferentes filósofos, especialistas y estudiosos del mundo, para presentar reflexiones de orden teórico en campos como la filosofía del lenguaje, la filosofía política contemporánea, filosofía de la religión, filosofía y feminismo, filosofía moderna, filosofía africana, filosofía latinoamericana, etc. Del mismo modo, esta publicación convoca la participación de Daniel Defert (2013, quien incluye una propuesta cronológica de la vida y el trabajo de Foucault y muestra varios hitos a partir de 1926 fecha de su nacimiento.

Así mismo, se resalta un segundo dossier publicado por la Cambridge University Press en el 2006 con el título The Cambridge companion to Foucault, cuya edición se hizo con la dirección del profesor Gary Gutting de la Universidad de Notre Dame.

Michel Foucault es, sin duda, el gestor de una propuesta analítica comprensiva, cuyos aportes teóricos corresponden a formulaciones con las cuales se puede teorizar en diferentes ámbitos del conocimiento. Tal vez referirse a ello y su obra lo encasillaría como filósofo, historiador o psicólogo, pero lo que es indiscutible es la relevancia de sus estudios críticos sobre las instituciones sociales (Foucault, 1979), la psiquiatría, el hospital, la medicina (Foucault, 1966), las ciencias humanas (Foucault, 2007), el manicomio, el sistema de prisiones, (Foucault, 1996) o la sexualidad humana(Foucault, 1991a). Así mismo, sus agudas reflexiones sobre el poder (Foucault, 1991b; 2002) y sus diferentes manifestaciones y sus formulaciones sobre el discurso (Foucault, 2005) le han merecido los mayores reconocimientos en el mundo académico y científico (Foucault, 2004).

Ese camino de manera clara y excepcional se iniciará en abril de 1954, cuando se publica Enfermedad mental y personalidad por Presses Universitaires de France, un pequeño escrito encargado por Althusser para una serie dirigida a los estudiantes que él denominó La verdadera psicología (Defert, 2013).

A continuación, en forma descriptiva daremos cuenta de los diferentes trabajos que dieron forma a ese pensamiento comprensivo.

\section{Foucault: en despedida}

Sin duda, la manera como Paul Veyne (2009) titula el capítulo 11 de su trabajo Foucault. Pensamiento y vida: "Retrato del samurái", evoca la gran valoración del pensamiento foucaultiano: 
Este supuesto izquierdista, que no era freudiano ni marxista, ni socialista ni progresista, ni tercermundialista, ni heideggeriano; que no leía a Bourdieu ni Le Figaro, que no era ni "nietzscheano de izquierdas" (como algunos), ni por supuesto de derechas, fue el inactual, el intemporal de su época, recuperando para definirlo un término justamente nietzscheano.

Las últimas noticias sobre Foucault eran malas. Mi mujer me había contado que los médicos del hospital de la Salpêtrière ya no sabía qué hacer. [...] Al lector de hoy le costará creer que a esas alturas (febrero de 1984) una fiebre y una tos no hicieran sospechar a nadie. El sida era, entonces, una plaga tan lejana e ignorada que se convertía en legendaria y quizá imaginaria [...] Ninguno de sus familiares sospechó nada; nosotros lo supimos después de que muriera. Según testimonios de Daniel Defert, él mismo anotó en sus cuadernos: "Sé que tengo el sida, pero con mi histeria lo olvido" [...] Por entonces se había instalado en mí una inquietud reprimida que se traducía en bromas chirriantes y repetidas sobre la salud de Foucault, que terminó estallando en una alucinación el mismo día que murió, el lunes 25 de junio de 1984 , unas horas antes de la llamada telefónica de un amigo, el especialista japonés Maurice Pinguet, que me comunicó el hecho desde Tokio, donde la radio acababa de dar la noticia (Veyne, 2009, pp. 147-154).

El 29 de junio de 1984 es sepultado en Vendreuvedu-Pitou (París).

\section{A modo de conclusión}

Puede afirmarse que la osadía de Foucault consistió en asumir un distanciamiento de los universales para interrogarlos desde su configuración histórica (Veyne, 2009). También que uno de sus grandes retos fue poner en sospecha la ruta de la linealidad del raciocinio como modo privilegiado del pensamiento.

\section{Referencias}

Gutting,G. (2006). The Cambridge Companion to Foucault. Cambridge UK: Cambridge University Press.

Canguilhem, G. (2005). Ideología y racionalidad en la historia de las ciencias de la vida. Buenos Aires: Amorrortu Editores.

Castro, E. (2014). Introducción a Foucault. Buenos Aires: Siglo XXI Editores.

Defert, D. (2013). Chronology. In C. Falzon., T. O’Leary., \& J. Sawicki (Eds.), A Companion to Foucault (pp. 11-83). Hoboken NJ: Wiley Blackwell.

Falzon, C., O’Leary, T., \& Sawicki, J. (2013). A Companion to Foucault. Hoboken, NJ: Wiley-Blackwell.

Foucault, M. (1966). El nacimiento de la clínica. Argentina: Siglo XXI Editores.

Foucault, M. (1979). Microfísica del poder. Madrid: Ediciones de la Piqueta.

Foucault, M. (1991a). Historia de la sexualidad. México: Siglo XXI Editores.

Foucault, M. (1991b). El sujeto y el poder. Bogotá: Carpe Diem Ediciones.

Foucault, M. (1996). Vigilar y castigar. México: Siglo XXI Editores.

Foucault, M. (2002). Defender la sociedad. México: Fondo de Cultura Económica.

Foucault, M. (2004). La arqueología del saber. Buenos Aires: Siglo XXI Editores.

Foucault, M. (2005). El orden del discurso. Barcelona: Tusquets Editores, S.A.

Foucault, M. (2007). Las palabras y las cosas. México: Siglo XXI Editores.

Veyne, P. (2009). Foucault. Pensamiento y vida. Barcelona: Paidós. 